\title{
Respiratory GPwSIs potential for integration or fragmentation?
}

\author{
Monica Fletcher
}

$\mathrm{T}$ he debate concerning the specialist versus the generalist role in general practice has been with us for many years. ${ }^{1}$ The current Government, by setting a target of 1,000 General Practitioners with a Special Clinical Interest (GPwSI) by the year 2004, ${ }^{2}$ clearly indicates where its views lie. This is possibly driven out of the belief that existing models of care fail to meet current patient expectations, and also that the role of primary care needs to be exploited further in the new NHS. The role of a GPwSI in respiratory disease will be an interesting development to follow and this is one specialism which is certainly attracting interest among respiratory aware general practitioners.

Much of the focus to date has been on the role of GPs with a special clinical interest and there has been little public debate on the nursing equivalent of such a role. Clinical specialism in nursing is not a new concept. ${ }^{3}$ Indeed, over the last few years the numbers of clinical nurse specialists in both secondary and primary care have been expanding as well as extending their role. Increasingly primary care organisations are appointing respiratory nurses to provide an enhanced clinical service and a strategic role to help shape local service provision. Although this development is exciting and well founded on the grounds of quality improvement, there are serious issues about the isolation experienced by many of these nurses, and this is a potential concern for the GPwSI role.

Last April, the Department of Health published a brief guide on implementing a scheme for nurses with special interests in primary care ${ }^{4}$ and in the introduction by the chief nursing officer she clearly indicates that the government sees great potential in support of a multidisciplinary approach to developing clinicians with a specialist clinical interest. In many ways this is a more logical model than either developing a pure GP or nurse specialist role and a model that has been given support by professionals working in the field of respiratory disease. ${ }^{5}$

We have come a long way in developing respiratory services in primary care and much of this has been achieved through the team management, so care needs to be taken that further development of specialist roles does not lead to fragmentation and the return of professional hegemony.

A final note of caution about these evolving specialist roles for doctors and nurses in primary care. We have to be conscious that by creating new 'specialist roles' in primary care, we are not merely shifting the specialist chasm from secondary care into primary care. There is a huge opportunity to redesign respiratory services and improve both the access and quality of care for patients. Let's make sure we do not miss that opportunity.

\section{References}

1. Heath I. The Mystery of General Practice The Nuffield Provincial Hospitals Trust, 1995.

2. Department of Health. The NHS Plan: A plan for investment, a plan for reform. The Stationery Office. London, 2000.

3. Carroll M Advanced nursing practice. Nursing

Standard 2002; 16(29):33-35.

4. Department of Health. Practitioners with a Specialist interest in Primary Care: Implementing a scheme for nurses with Special Interests in Primary Care. London, 2003.

5. Williams S, Ryan D, Price D, Langley C, Fletcher M.and Everden P. General Practitioners with a special clinical interest: a model for improving respiratory disease management. BJGP 2002; 52:838-42.

\author{
Monica Fletcher \\ Chief Executive \\ Correspondence to: \\ Monica Fletcher \\ National Respiratory \\ Training Centre \\ The Athenaeum \\ Church Street \\ Warwick
}

Tel +44 (0)1926 493313

Email:

m.fletcher@nrtc.org.uk

Date submitted: $31 / 05 / 03$

Date Accepted: 01/06/03

Prim Care Resp J 2003; 12(2):37 